(1)

CrossMark

\title{
Characterisation of eppin function: expression and activity in the lung
}

\author{
Aaron Scott ${ }^{1,7}$, Arlene Glasgow ${ }^{1,7}$, Donna Small ${ }^{1}$, Simon Carlile ${ }^{1}$, \\ Maelíosa McCrudden ${ }^{2}$, Denise McLean ${ }^{2}$, Ryan Brown ${ }^{1}$, Declan Doherty ${ }^{1}$, \\ Fionnuala T. Lundy², Umar I. Hamid ${ }^{2}$, Cecilia M. O'Kane², Daniel F. McAuley², \\ Malcolm Brodlie ${ }^{3}$, Michael Tunney ${ }^{4}$, J. Stuart Elborn ${ }^{2}$, Chris R. Irwin ${ }^{5}$, \\ David J. Timson $\mathbb{1}^{6}$, Clifford C. Taggart ${ }^{1}$ and Sinéad Weldon ${ }^{1}$
}

Affiliations: ${ }^{1}$ Airway Innate Immunity Research Group, Centre for Experimental Medicine, Wellcome-Wolfson Institute for Experimental Medicine, Queen's University Belfast, Belfast, UK. ${ }^{2}$ Centre for Experimental Medicine, Wellcome-Wolfson Institute for Experimental Medicine, Queen's University Belfast, Belfast, UK. ${ }^{3}$ Paediatric Respiratory Unit, Great North Children's Hospital and Institute of Cellular Medicine, Newcastle University, Newcastle upon Tyne, UK. ${ }^{4} \mathrm{Halo}$, School of Pharmacy, Queen's University Belfast, Belfast, UK ${ }^{5}$ Centre for Dentistry, Queen's University Belfast, Belfast, UK. ${ }^{6}$ School of Pharmacy and Biomolecular Sciences, University of Brighton, Brighton, UK. ${ }^{7}$ Joint first authors.

Correspondence: Cliff Taggart, Airway Innate Immunity Research Group, Centre for Infection and Immunity, Wellcome-Wolfson Institute for Experimental Medicine, Queen's University Belfast, Belfast, BT9 7BL, UK. E-mail: c.taggart@qub.ac.uk

@ERSpublications

Eppin is a low-molecular-weight protein which is expressed in the human lung during inflammation http://ow.ly/WZuQ30aELEI

Cite this article as: Scott A, Glasgow A, Small D, et al. Characterisation of eppin function: expression and activity in the lung. Eur Respir J 2017; 50: 1601937 [https://doi.org/10.1183/13993003.01937-2016].

ABSTRACT Eppin is a serine protease inhibitor expressed in male reproductive tissues.

The aim of this study was to investigate the localisation and regulation of eppin expression in myeloid and epithelial cell lines, and explore its potential role as a multifunctional host defence protein.

Using immunohistochemistry and Western blotting, eppin was detected in the lungs of patients with acute respiratory distress syndrome and cystic fibrosis lung disease. Expression of eppin in monocytic cells was unaffected by stimulation with Toll-like receptor agonists, cytokines and hormone receptor agonists. However, upregulated expression and secretion of eppin was observed following treatment of monocytes with epidermal growth factor. Incubation of recombinant eppin with monocytic cells resulted in significant inhibition of lipopolysaccharide-induced chemokine production. Furthermore, eppin inhibited lipopolysaccharide-induced NF- $\mathrm{B}$ activation by a mechanism which involved accumulation of phosphorylated I $\mathrm{I} \mathrm{B} \alpha$. In an in vivo model of lung inflammation induced by lipopolysaccharide, eppin administration resulted in decreased recruitment of neutrophils to the lung with a concomitant reduction in the levels of the neutrophil chemokine macrophage inflammatory protein-2.

Overall, these results suggest a role for eppin outside of the reproductive tract and that eppin may have a role in the innate immune response in the lung.

This article has supplementary material available from erj.ersjournals.com

Received: Oct 032016 | Accepted after revision: March 292017

Support statement: The study was funded by the Dept for Employment and Learning, Northern Ireland (A. Scott and C.C. Taggart), Medical Research Council Clinician Scientist Fellowship (MR/M008797/1) (M. Brodlie) and the Health Research Board of Ireland (RP/2006/59) (S. Weldon and C.C. Taggart). Funding information for this article has been deposited with the Crossref Funder Registry.

Conflict of interest: None declared.

Copyright OERS 2017 


\section{Introduction}

Human epididymal protease inhibitor (eppin, SPINLW1, WFDC7) is a cysteine-rich protein comprised of both a Kunitz-type and a WAP (whey acidic protein) four-disulfide core (WFDC) protease inhibitor consensus motif $[1,2]$. In the epididymis, eppin is secreted by epithelial cells and is a key component in the eppin protein complex which mediates the capacitation of spermatozoa [3]. In this role, eppin acts as a serine protease inhibitor, inhibiting the action of prostate-specific antigen [4], while protecting the spermatozoa from potential damage by bacteria [3,5]. The majority of work on eppin to date has therefore focused on the development of eppin as a target for a male contraceptive based on inhibition of the eppin protein complex via specific antibodies [6].

Although eppin is a serine protease inhibitor, the arrangement of cysteine residues differs from that of secretory leukocyte protease inhibitor (SLPI) and elafin, the two most prominent members of the WFDC family [7]. Similar to SLPI and elafin, recombinant eppin inhibited elastase activity, but unlike SLPI, eppin had no effect on trypsin or chymotrypsin activities [8-11]. Split domain studies demonstrated that the serine antiprotease activity resides solely in the Kunitz domain of eppin, while the WFDC domain retains no antiprotease activity [9]. Like SLPI [12], findings suggest that eppin also possesses antibacterial activity against Escherichia coli and that this effect is mediated via membrane permeabilisation [5]. In contrast to its antiprotease activity, the antibacterial activity of eppin against E. coli appears to be mediated by both the WFDC and Kunitz domains, with maximal killing achieved by the full-length protein [9].

On the basis of their multiple functions, WFDC proteins are considered to play key roles in innate immunity at mucosal surfaces. In contrast to eppin, elafin and SLPI are constitutively expressed by a variety of cell types, including respiratory and intestinal epithelia as well as key cell types involved in the innate immune response such as mast cells, neutrophils and macrophages [13-19]. Furthermore, SLPI and elafin expression is altered in response to a number of factors, including pro-inflammatory cytokines, bacterial products, proteases and androgens [16, 20-22]. The anti-inflammatory activity of SLPI and elafin in vitro and in vivo is well documented and reviewed elsewhere [7, 23, 24]. Previous work has shown that SLPI is capable of inhibiting lipopolysaccharide (LPS)-induced responses [20, 25-27]. In addition, elafin inhibited LPS activation of monocytic cells by inhibiting NF- $\kappa \mathrm{B}$ activation via a process partly involving accumulation of polyubiquitinated $I \kappa B \alpha$ [28]. Little is known about the function of eppin outside of the epididymis. In this study, we expand current knowledge on the localisation and regulation of eppin expression, and explore its potential role as a multifunctional host defence protein.

Methods

Full details are available in the supplementary material.

\section{Cell culture}

Unless otherwise indicated, cell culture reagents were obtained from Life Technologies (Paisley, UK). Human acute monocytic leukaemia cells (THP-1), myelomonocytic cells (U937) and type II alveolar epithelial cells (A549) were purchased from the American Type Culture Collection (Manassas, VA, USA). Human diploid myeloid leukaemia cells (PLB-985) were obtained from the German Collection of Microorganisms and Cell Cultures (DSMZ, Braunschweig, Germany). The human bronchial epithelial cell line 16HBE14o- (HBE), the cystic fibrosis (CF) bronchial epithelial cell line CFBE41o- homozygous for the F508del mutation (CFBE), the human tracheal epithelial cell line 9HTEo- (HTE) and the CF tracheal epithelial cell line CFTE29o- homozygous for the F508del mutation (CFTE) were obtained as a gift from Dieter Gruenert (California Pacific Medical Center Research Institute, San Francisco, CA, USA) [29, 30].

\section{Recombinant protein production}

Recombinant eppin was produced as described previously [9].

\section{Analysis of secreted eppin}

THP-1 monocytic cells were incubated in serum-free media for $8 \mathrm{~h}$ in the absence or presence of epidermal growth factor (EGF; $5 \mathrm{ng} \cdot \mathrm{mL}^{-1}$ ) (Peprotech, London, UK). Supernatants were collected and protein precipitated using a method outlined in the supplementary material and adapted from Wessel and FugGE [31].

\section{Human lung tissue}

Lungs harvested from potential donors that were found to be unsuitable for transplantation were obtained from the International Institute for Advancement of Medicine (Edison, NJ, USA). Ethical approval for the use of these samples was obtained from the Queen's University Belfast School of Medicine, Dentistry and Biomedical Science Research Ethics Committee (Belfast, UK). The lungs were perfused ex vivo based on previously described methods [32,33]. Experimentation ceased $4 \mathrm{~h}$ after LPS instillation, upon which tissue samples for histology were taken from LPS-perfused lobes [32]. Lung tissue sections from CF 
patients were obtained from the University of Newcastle (Newcastle upon Tyne, UK). Ethical approval for the use of these tissue samples was obtained from the Newcastle and North Tyneside Ethics Committee (11/NE/0291).

Immunostaining of human tissue for eppin

Immunostaining for eppin detection was performed similar to previous methods [32].

\section{Statistical analysis}

All data were analysed using Prism 5.0 (GraphPad, San Diego, CA, USA). Means were compared by the unpaired t-test, Mann-Whitney test, one-way ANOVA, Kruskal-Wallis test or one-sample t-test compared with 100 for densitometry data as appropriate. $\mathrm{p}<0.05$ was accepted to indicate statistical significance. Data represent mean \pm SEM of $n=3$ unless otherwise stated.

\section{Results}

Eppin is expressed in myeloid and airway epithelial cells

Given that SLPI and elafin transcripts are found in a variety of cell types, we first investigated whether eppin had a similar pattern of expression. As expected, eppin expression was detected in testes and lung tissue, albeit to a lesser extent in the lung tissue (figure 1a). Eppin expression was also detected in myeloid cell lines, such as THP-1 and U937 monocytic cells, monocyte-derived macrophages, and neutrophils differentiated from PLB-985 cells (figure 1a). Furthermore, eppin was expressed in both human primary peripheral blood mononuclear cells (PBMCs) (figure 1b) and polymorphonuclear leukocytes (PMNs) (figure 1a). Expression of eppin was also detected in epithelial cell lines of the respiratory tract including human type II alveolar cells (A549), as well as tracheal and bronchial epithelial cell lines (figure 1b). Eppin expression was highest in testes, and expression of eppin in the other tissues/cells (relative to eppin at 100\%) was: THP-1 monocytes 80\%, THP-1 macrophages 75\%, U937 monocytes 65\%, U937 macrophages 55\%, PLB-985 cells 57\%, PMNs 80\%, A549 cells 39\%, lung 47\%, PBMCs 24\%, HTE 17\%, CFTE 17\%, HBE $24 \%$ and CFBE $22 \%$, as determined by densitometry. Sequencing of PCR products confirmed the identity of human eppin.

Detection of eppin in human lung tissue, bronchoalveolar lavage fluid and sputum

Human lungs were perfused with LPS as outlined in the supplementary material. Tissue samples from non-LPS-perfused lobes, from LPS-perfused lobes and from CF patients were used for

a)
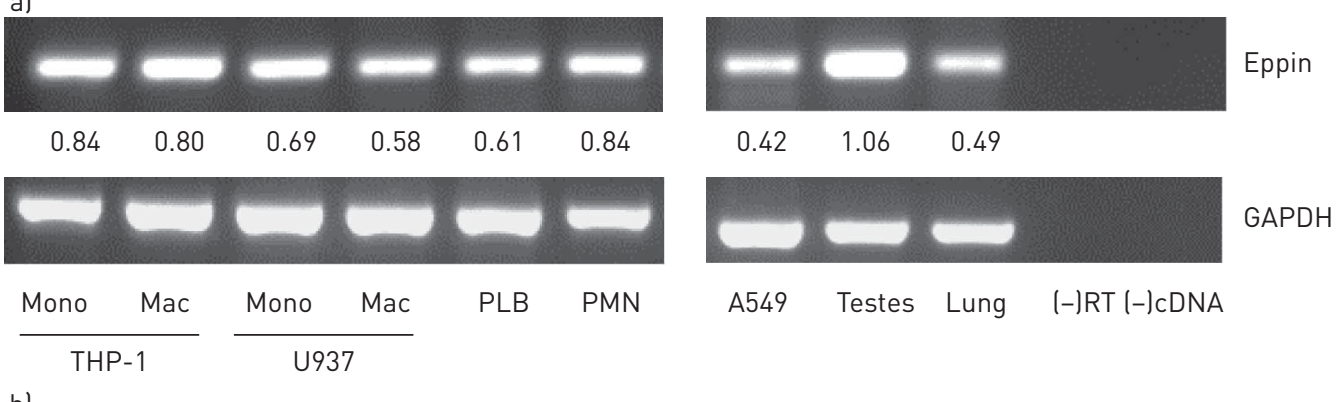

Eppin

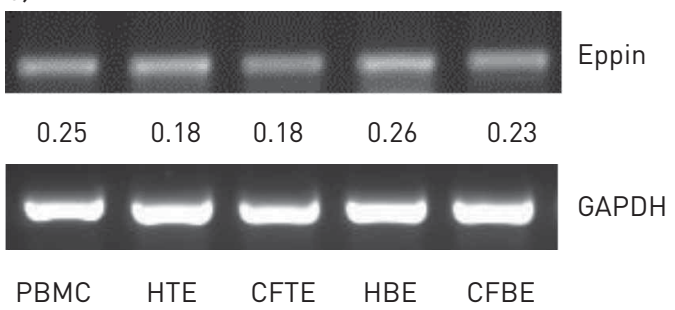

FIGURE 1 Basal expression profile of eppin in cell lines and primary cells. Eppin and glyceraldehyde 3-phosphate dehydrogenase (GAPDH) expression were detected in a) THP-1 and U937 monocytic (Mono) and monocyte-derived macrophages (Mac), PLB-985 differentiated neutrophils (PLB), primary human neutrophils (PMN), human type II alveolar (A549) cells, testes and lung tissue, and b) human peripheral blood mononuclear cells (PBMC), human tracheal (HTE) and cystic fibrosis (CF) tracheal (CFTE), and human bronchial (HBE) and CF bronchial epithelial (CFBE) cell lines by reverse transcriptase-PCR (35 cycles) as outlined in the supplementary material. Levels of eppin expression relative to GAPDH expression (eppin/ GAPDH) are shown between panels. 
immunohistochemistry. Some eppin staining was present in non-LPS-perfused lung tissue (figure 2a), and was particularly evident in the LPS-perfused (figure 2b) and CF patient (figure 2c) lung tissues. In agreement with the eppin expression data outlined in figure 1, positive staining was prominent in epithelial and immune cells using two different eppin antibodies, confirming the presence of eppin in the in vivo lung. In addition, eppin was shown to be present in bronchoalveolar lavage fluid (BALF) from patients with acute respiratory distress syndrome (ARDS) and in sputum from patients with CF, but was not present in BALF from healthy volunteers (figure 3). Eppin was detected as the same high-molecular-weight complex in ARDS BALF and CF sputum, which has been shown previously in semen where eppin is complexed to other proteins including clusterin and lactoferrin [3]. There appear to be low microgram amounts of eppin in CF sputum and ARDS BALF as determined by densitometry of the CF sputum and ARDS BALF blots. Other lower molecular weight bands were detectable in CF sputum, which may represent proteolytic breakdown products of the eppin complex.

Eppin expression and secretion are upregulated by EGF

In order to investigate factors that may affect eppin expression, THP-1 cells were stimulated with a range of inflammatory agonists and effects on eppin expression were assessed by reverse transcriptase (RT)-PCR. A number of Toll-like receptor (TLR) agonists such as LPS (TLR4), $\mathrm{Pam}_{3} \mathrm{CysSK}_{4}$ (TLR2) and polyinosinic-polycytidylic acid (TLR3) had no effect on eppin expression (data not shown). Hormone receptor agonists such as oestradiol and progesterone are known inducers of SLPI expression [21, 22].

a)

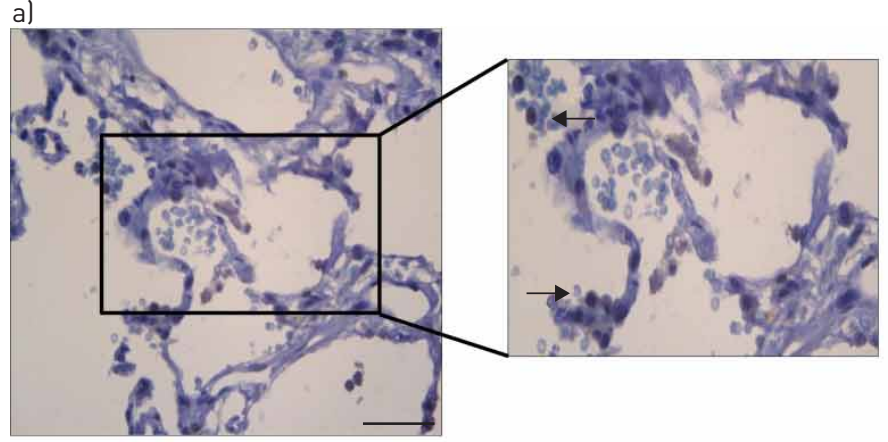

c)

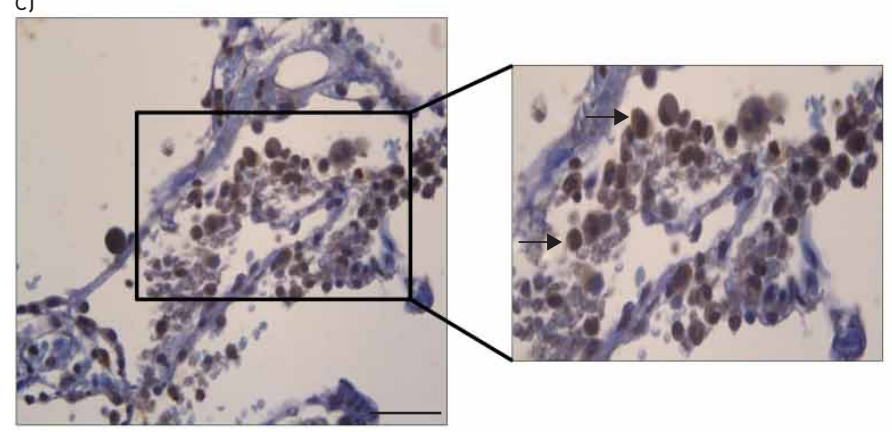

e)

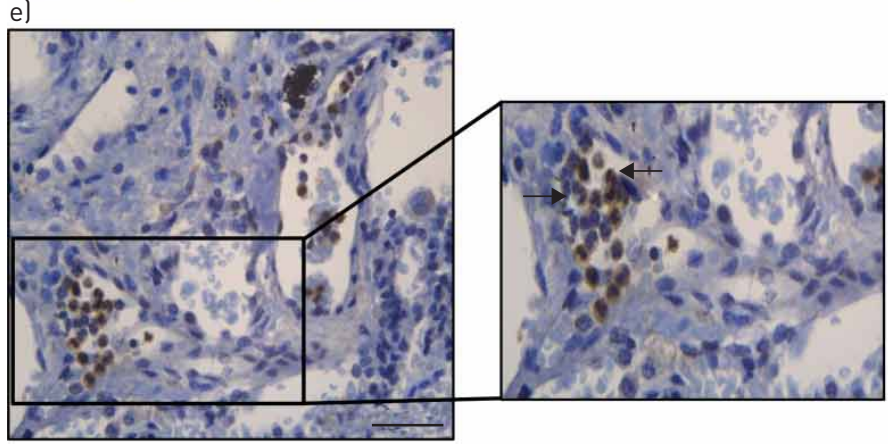

b)

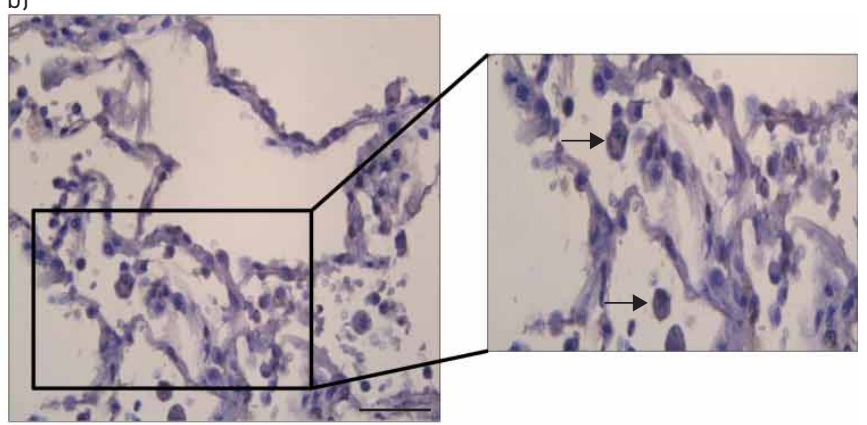

d)

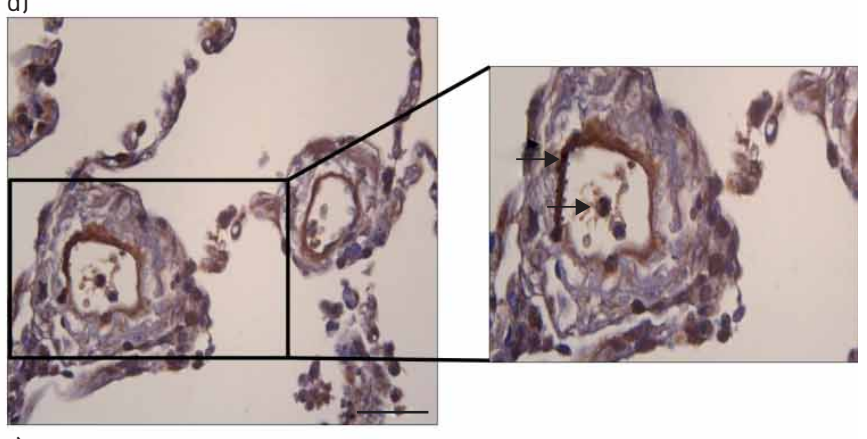

f)

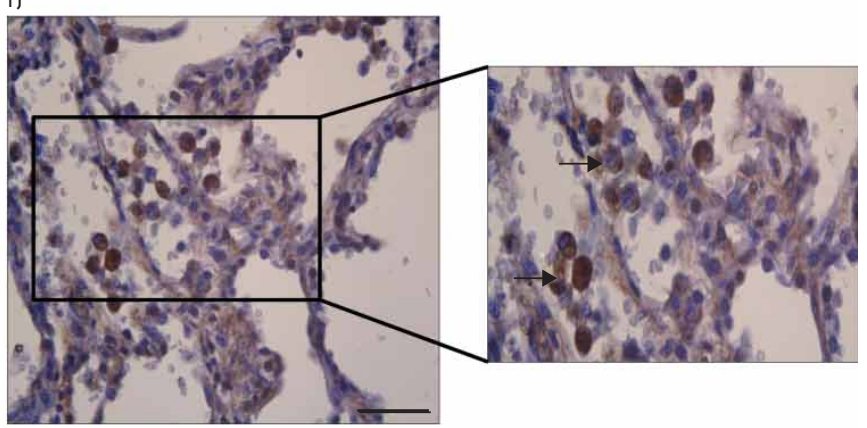

FIGURE 2 a-f) Detection of eppin in human lung tissue. Tissue samples from a, b) ex vivo non-LPS-perfused lungs, c, d) LPS-perfused lungs and $e, f)$ cystic fibrosis lungs were formalin-fixed and paraffin-embedded for immunohistochemistry. Tissue sections were stained with two rabbit anti-human eppin antibodies from a, c, e) Santa Cruz (Heidelberg. Germany) or b, d, f) Abbexa (Cambridge, UK) (see supplementary material) and representative images $(n=2)$ were taken at $\times 20$ objective lens magnification. Scale bar: $50 \mu \mathrm{m}$. Further zoomed in images (to the right of the main panels) were also taken to highlight cellular staining of eppin. Areas of eppin staining are indicated by arrows. 

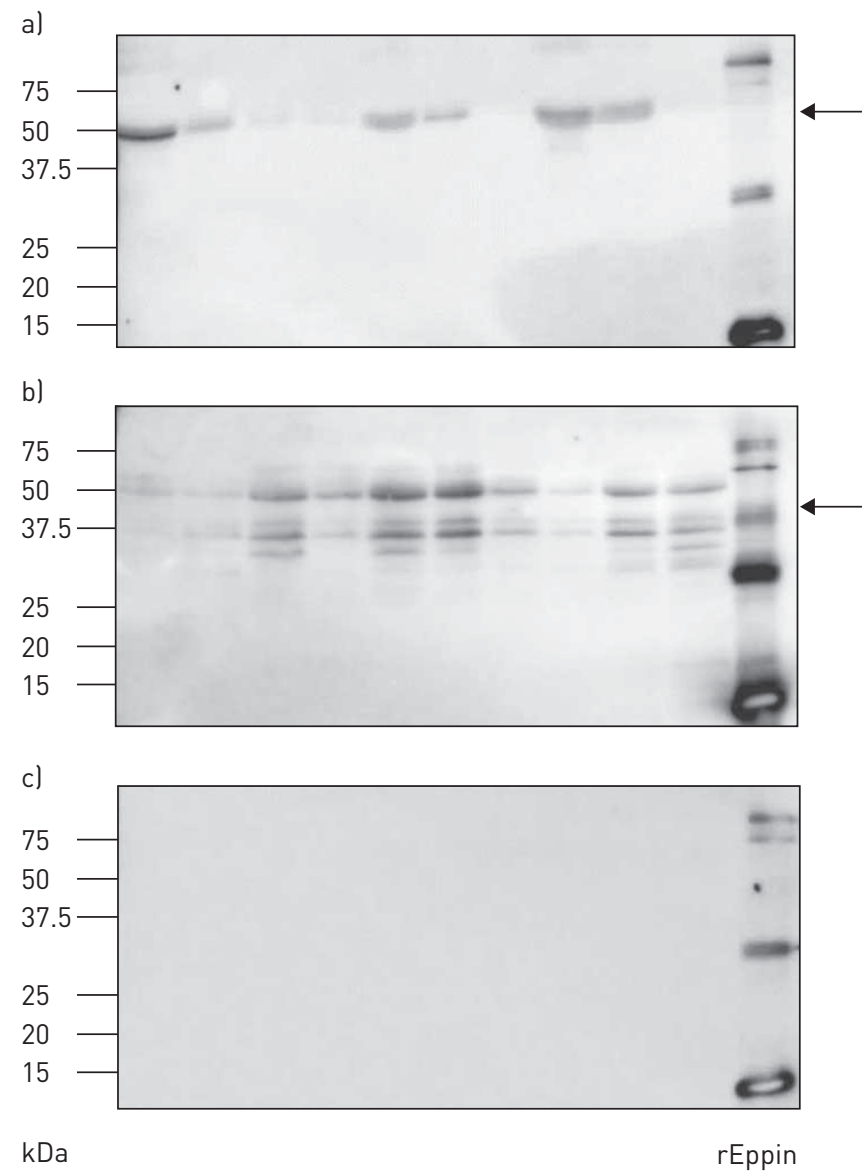

FIGURE 3 Detection of eppin in airway secretions. a) Acute respiratory distress syndrome patient bronchoalveolar lavage fluid (BALF) samples, b) cystic fibrosis sputum and c) healthy control BALF samples were electrophoresed and blotted for eppin (Abbexa). Recombinant eppin (rEppin) was run in each blot and migrated as monomeric, dimeric and trimeric bands. Molecular weight markers ( $\mathrm{kDa}$ ) are indicated to the left of each blot and the position of the eppin complex indicated with arrows.

a)
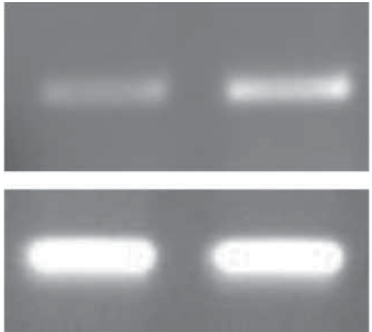

Control b)

GAPDH

EGF

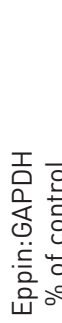

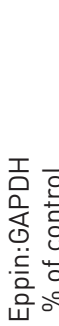

$$
200
$$

50

0

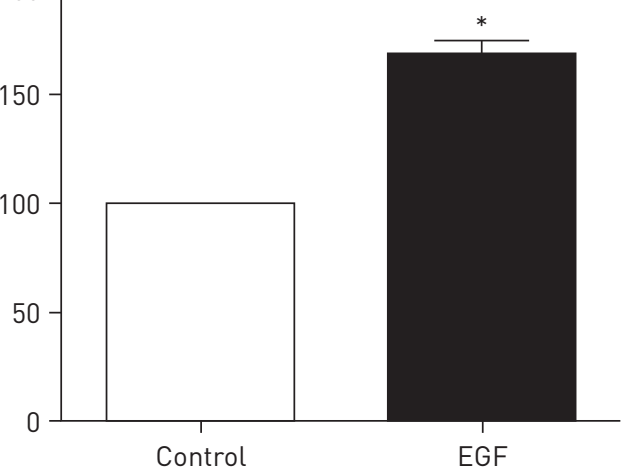

FIGURE 4 Eppin is upregulated by epidermal growth factor (EGF) stimulation. a) THP-1 monocytic cells were incubated with media alone (control) or with EGF ( $5 \mathrm{ng} \cdot \mathrm{mL}^{-1}$ ) for $8 \mathrm{~h}$ and eppin expression detected by reverse transcriptase-PCR ( 35 cycles) as outlined in the supplementary material. b) Densitometry of eppin relative to glyceraldehyde 3-phosphate dehydrogenase (GAPDH). *: p<0.05. c) Supernatants from control and EGF-treated cells were concentrated by methanol/chloroform precipitation and eppin was detected by Western blot. The identity of eppin was confirmed by reversed-phase chromatography. The two main peptides obtained from this analysis were ANCLNTCK and DRQCQDNKK, both of which demonstrate $100 \%$ overlap with human eppin. 
However, oestradiol or progesterone did not modulate eppin expression (data not shown). Growth factors such as EGF and transforming growth factor (TGF)- $\beta$ have also been shown to regulate SLPI expression $[34,35]$. To investigate a possible role for growth factors in the modulation of eppin expression, THP-1 monocytic cells were stimulated with EGF, TGF- $\beta$ and fibroblast growth factor (FGF) at a range of concentrations. TGF- $\beta$ and FGF treatment of monocytes had no effect on eppin expression (data not shown). However, eppin expression was increased after treatment with EGF (figure $4 \mathrm{a}$ and b). In agreement with this result, analysis of cell supernatants by Western blotting revealed the presence of increased levels of eppin in EGF-treated cell supernatants (figure 4c). The identity of eppin was confirmed by digestion of protein in SDS-PAGE pieces from EGF-treated cell supernatant followed by electrospray ionisation mass spectrometry (see supplementary material) to identify the protein present in the SDS-PAGE samples. The two main peptides obtained from this analysis were ANCLNTCK and DRQCQDNKK, both of which demonstrate $100 \%$ overlap with human eppin.

\section{Effect of recombinant eppin on bacterial growth}

To investigate a potential role for eppin as a host defence protein in the lung, we expressed and purified recombinant human eppin. The ability of eppin to permeabilise clinically relevant Gram-negative and Gram-positive bacteria as a method of bacterial killing was compared with LL-37, a well-known antimicrobial peptide. Eppin permeabilised P. aeruginosa (figure 5a) and Staphylococcus aureus (figure 5b) bacterial strains, which was comparable to, if not better than, the permeabilisation observed with LL-37, particularly in the case of $P$. aeruginosa. Eppin also inhibited the growth of $P$. aeruginosa and $S$. aureus when assessed by radial diffusion assay, and, once again, had a significant effect on P. aeruginosa growth (figure 5c).

a)

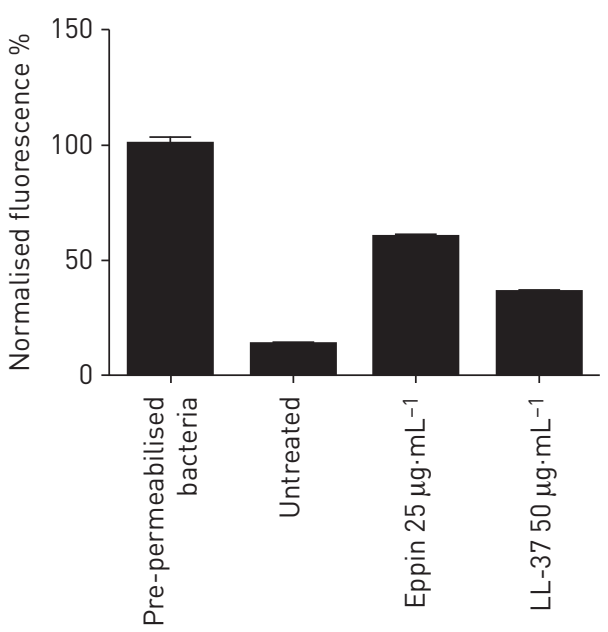

c)

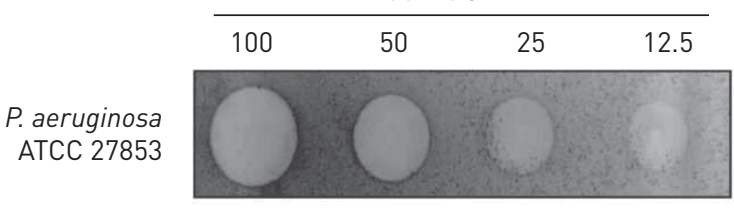

S. aureus ATCC 25923

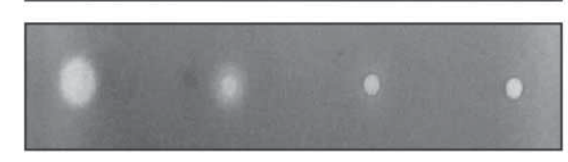

b)

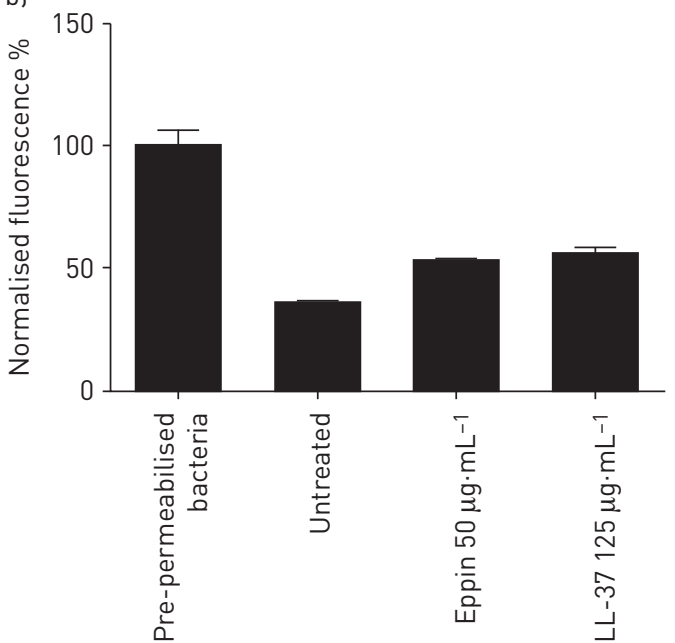

Cecropin A Control $\quad 100 \mu \mathrm{g} \cdot \mathrm{mL}^{-1}$
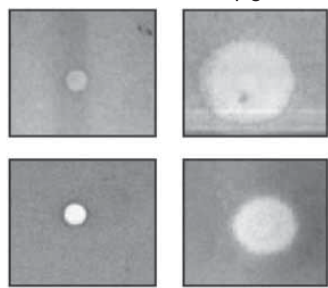

FIGURE 5 Eppin permeabilises Gram-negative and Gram-positive bacteria. a) Pseudomonas aeruginosa and b) Staphylococcus aureus were incubated for $2 \mathrm{~h}$ with $5 \mu \mathrm{M}$ SYTOX Green nucleic acid stain (Invitrogen, Carlsbad, CA, USA) with or without eppin or LL-37 as indicated. The proportion of permeabilised bacteria was quantified by measuring the relative fluorescence at $480 \mathrm{~nm}$ (excitation) and emission between 510 and $700 \mathrm{~nm}$ using a SPECTRAmax Gemini XS fluorescence microplate reader (Molecular Devices, Wokingham, UK), and results are expressed as a percentage of the pre-permeabilised positive control. c) In radial diffusion assays, agarose gels were prepared containing $P$. aeruginosa or $S$. aureus and incubated with increasing concentrations of recombinant eppin $\left(12.5-100 \mu \mathrm{g} \cdot \mathrm{mL}^{-1}\right)$ or cecropin $\mathrm{A}\left(100 \mu \mathrm{g} \cdot \mathrm{mL}^{-1}\right)$ as a positive control. 
a)
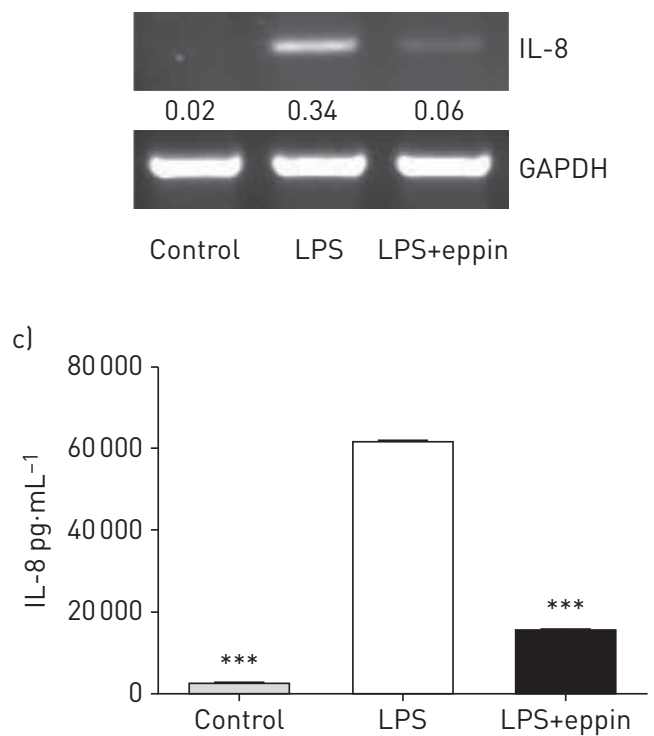

e)

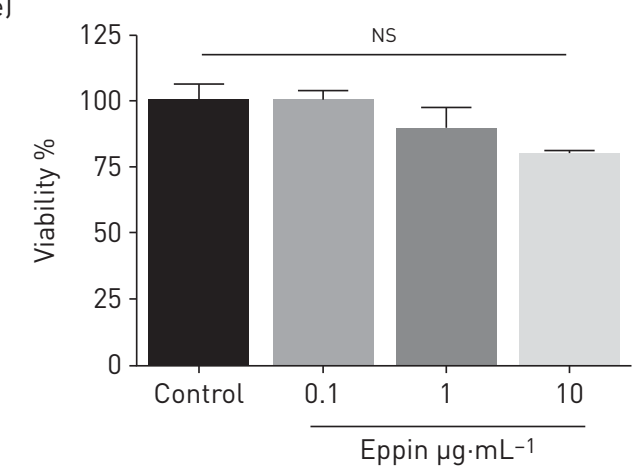

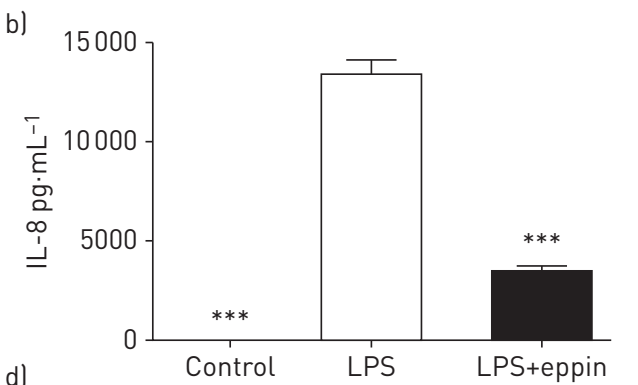

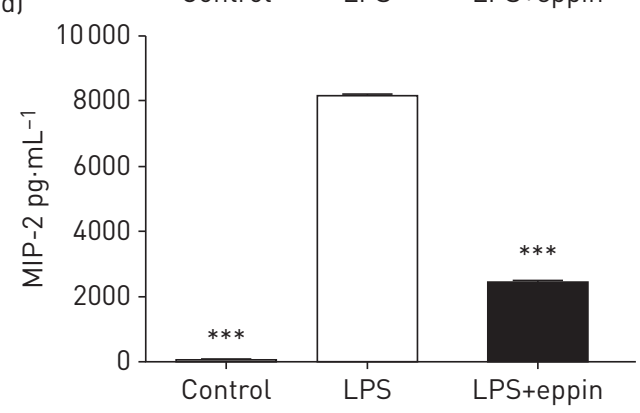

FIGURE 6 Eppin inhibits lipopolysaccharide (LPS)-induced cytokine production in mononuclear cells. a) THP-1 monocytic cells were pre-treated with recombinant human eppin $\left(5 \mu \mathrm{g} \cdot \mathrm{mL}^{-1}\right)$ for $1 \mathrm{~h}$ prior to $6 \mathrm{~h}$ LPS stimulation. Total RNA was extracted and reverse transcriptase-PCR performed for interleukin (IL)-8 and glyceraldehyde 3-phosphate dehydrogenase (GAPDH) as described in the Methods section. Expression levels of IL-8 relative to GAPDH (IL-8/GAPDH) are shown between the panels. b) THP-1 monocytic cells were pre-treated with recombinant human eppin $\left(5 \mu \mathrm{g} \cdot \mathrm{mL}^{-1}\right)$ for $1 \mathrm{~h}$ prior to LPS stimulation. Cell-free supernatants were collected after $24 \mathrm{~h}$ LPS stimulation and levels of IL-8 were quantified by ELISA. c) THP-1 monocyte-derived macrophages and d) murine bone marrow-derived macrophages were pre-treated with recombinant human eppin $\left(5 \mu \mathrm{g} \cdot \mathrm{mL}^{-1}\right)$ for $1 \mathrm{~h}$ prior to $24 \mathrm{~h}$ LPS stimulation. Levels of $\mathrm{c}$ ) human IL-8 and d) murine macrophage inflammatory protein (MIP)-2 were quantified by ELISA. ${ }^{* * *}: p<0.001$ versus LPS. e) THP-1 monocytic cells were incubated in cell medium or with recombinant human eppin $10.1,1$ and $10 \mu \mathrm{g} \cdot \mathrm{mL}^{-1}$ ) for $24 \mathrm{~h}$. Cell viability was assessed using Vision Blue Quick Cell Viability Assay reagent (Source Bioscience, Nottingham, UK). Ns: nonsignificant.

\section{Effect of recombinant eppin on LPS-induced cytokine production}

Previous work has shown that the related WFDC proteins SLPI and elafin can modulate LPS signalling in monocytic cells [26-28]. Pre-incubation of THP-1 monocytic cells with eppin for $1 \mathrm{~h}$ prior to LPS stimulation significantly inhibited both the expression (figure 6a) and production of interleukin (IL)-8 (figure 6b). In addition, eppin pre-incubation inhibited LPS-induced production of IL- 8 from THP-1 monocyte-derived macrophages (figure $6 \mathrm{c}$ ) and macrophage inflammatory protein (MIP)-2 from murine bone marrow-derived macrophages (BMDMs) (figure 6d). We also observed no significant effect of eppin on THP-1 cell viability (figure 6e).

\section{Effects of eppin on $N F-\kappa B$ activation}

To investigate further the effect of eppin on the LPS signalling pathway, we evaluated the impact of eppin on LPS-induced activation of NF- $\kappa \mathrm{B}$. Eppin significantly inhibited LPS-induced p65-DNA binding activity in THP-1 nuclear extracts (figure 7a), thereby suggesting that the ability of eppin to inhibit LPS-induced cytokine expression may be mediated via its effects on the NF- $\kappa \mathrm{B}$ signalling pathway. SLPI has previously 
a)

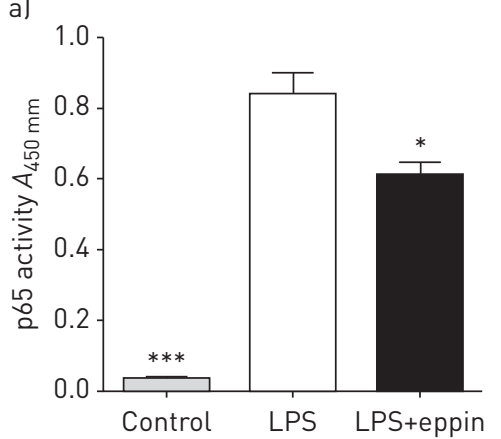

b)

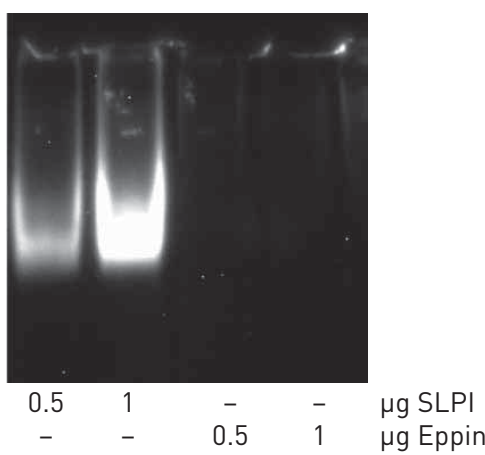

c)

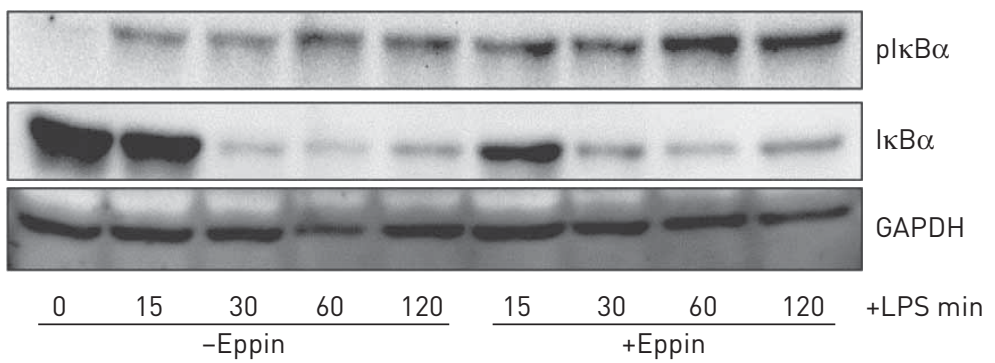

FIGURE 7 Eppin decreases lipopolysaccharide (LPS)-induced NF-kB activation in THP-1 monocytic cells and increases levels of phosphorylated $I \kappa B \alpha$. a) THP-1 monocytic cells were pre-treated with recombinant human eppin $\left(5 \mu \mathrm{g} \cdot \mathrm{mL}^{-1}\right)$ for $1 \mathrm{~h}$ followed by stimulation with LPS for $60 \mathrm{~min}$. Nuclear lysates were prepared and p65 subunit activity determined using a TransAM activity ELISA (Active Motif, La Hulpe, Belgium). *: p<0.05 versus LPS; ${ }^{* * *}$ : $p<0.001$ versus LPS. b) The binding of eppin to the consensus NF-kB binding site was determined by electrophoretic mobility shift assay. SLPI: secretory leukocyte protease inhibitor. c) THP-1 monocytic cells were pre-treated with recombinant human eppin $\left(5 \mu \mathrm{g} \cdot \mathrm{mL}^{-1}\right)$ for $1 \mathrm{~h}$ followed by stimulation with LPS for 0-120 min. Cytoplasmic lysates were immunoblotted for $\mid \kappa B \alpha$, phospho- $\mid \kappa B \alpha(p / \kappa B \alpha ;$ Ser32/36) and glyceraldehyde 3-phosphate dehydrogenase (GAPDH).

been shown to inhibit LPS-induced NF- $\kappa B$ activity by competing with the p65 subunit for binding to consensus sites in the promoter regions of target genes such as IL-8 [27]. However, in contrast to SLPI, eppin was unable to bind NF- $\mathrm{B}$ consensus oligonucleotides (figure $7 \mathrm{~b}$ ). Eppin's effect on LPS signalling upstream of NF- $\kappa B$ was evaluated by Western blotting. LPS-induced degradation of I $\mathrm{B} \alpha$ was observed in samples over time regardless of whether eppin was present or not (figure 7c). However, increased

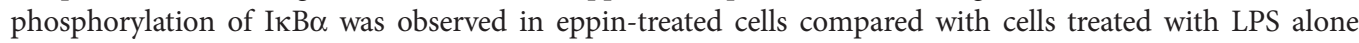
(figure 7c).

\section{Eppin inhibits LPS-induced lung neutrophil recruitment in vivo}

To determine if eppin might alter LPS effects in vivo, the effects of eppin in an in vivo model of LPS-induced acute lung inflammation were investigated. Mice receiving eppin exhibited a significant reduction in pulmonary total cell counts following intratracheal LPS administration (figure 8a) with a significant decrease in neutrophil counts (figure $8 \mathrm{~b}$ ). This decrease in neutrophil infiltration was associated with a reduction in levels of the neutrophil chemoattractant MIP-2 in BALF from mice that received eppin and LPS compared with LPS alone (figure 8c). These data confirm the in vitro findings for MIP-2 shown in figure $5 \mathrm{~d}$ and suggest that eppin may play an immunomodulatory role in the airways by reducing LPS-induced MIP-2 production from host cells with a subsequent reduction in neutrophil recruitment.

\section{Discussion}

The majority of work on eppin to date has focused on its role within the male reproductive tract. In this study, we identified novel sites of eppin expression in both myeloid and epithelial cell types. Furthermore, eppin expression was confirmed in primary mononuclear cells and neutrophils. We also demonstrated the presence of eppin in tissue and airways (BALF and sputum) from patients with ARDS and CF, as well as from human ex vivo lung tissue perfused with LPS. Given the similar sites of expression we demonstrated between eppin and other WFDC genes, we examined whether the expression of eppin in monocytic cells was modulated by factors known to regulate the expression of SLPI and/or elafin. However, we found that eppin expression was not induced by various TLR agonists, hormone receptor agonists and cytokine stimuli used in this study. 

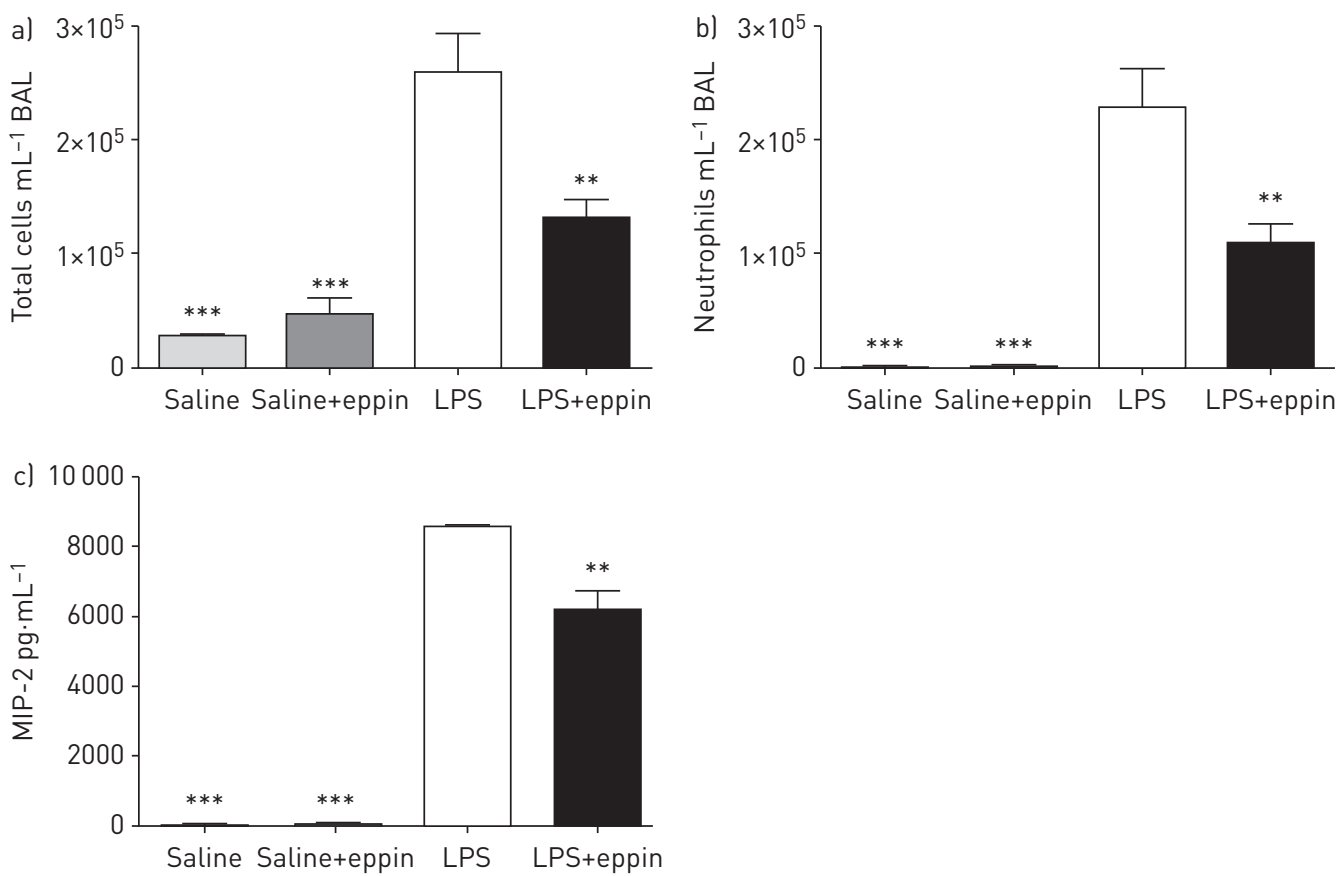

FIGURE 8 Recombinant eppin decreases lipopolysaccharide (LPS)-induced neutrophil recruitment in a mouse model of acute lung inflammation. Mice received intratracheal saline or LPS with or without recombinant eppin and after $4 \mathrm{~h}$ mice were sacrificed and bronchoalveolar lavage (BAL) performed. a) Total cell counts and b) neutrophil counts were quantified. c) Levels of macrophage inflammatory protein (MIP)-2 in BAL fluid were quantified by ELISA. $n=3-7$ per group. ${ }^{* *}: p<0.01$ versus LPS; ${ }^{* * *}: p<0.001$ versus LPS.

These findings are similar to those reported for HE4 (WFDC2), another WFDC family member. HE4 was originally thought to be limited to the reproductive tract; however, the expression profile of HE4 has since expanded to include the trachea, lung and nasal epithelium as well as major and minor salivary glands $[13,36]$. HE4 expression was not affected by pro-inflammatory agonists such as IL-1 $\beta$ and tumour necrosis factor- $\alpha$ [14]. Although SLPI expression is induced by hormone receptor agonists such as oestradiol and progesterone, elafin expression is unaffected [21, 22]. In addition, growth factors have been shown to regulate SLPI expression in vitro and in vivo [34, 35, 37]. In this study, eppin expression in monocytic cells was unaffected by oestradiol and progesterone treatment (data not shown); however, both eppin expression and secretion were upregulated by EGF treatment. We have also provided evidence of eppin protein in the lungs of patients with CF and ARDS by immunohistochemistry and Western blot, indicating that eppin is increased during inflammation with little eppin present in healthy lung. It should be highlighted that further confirmation of eppin presence in diseased lung could be provided by the availability of more specific monoclonal antibodies to eppin as there is a paucity of eppin antibodies available to carry out definitive in vivo studies. However, our immunohistochemistry and Western blot data do correlate to the eppin expression detected in lung epithelial and inflammatory cells as shown in figure 1. Eppin was not detected as a monomeric species in CF and ARDS airway secretions, but was present as a high-molecular-weight complex or oligomeric species in these biological fluids, which has been shown previously in semen where eppin is complexed to other proteins including clusterin and lactoferrin [3].

For the purposes of investigating a potential host defence role for eppin, we expressed and purified recombinant eppin [9]. Our subsequent analyses focused on exploring the antibacterial and immunomodulatory potential of eppin. Recombinant eppin has previously been shown to inhibit growth of E. coli $[5,9]$. In this study, we expand these observations by demonstrating an antibacterial effect of eppin against $P$. aeruginosa and $S$. aureus, two clinically relevant pulmonary pathogens. Although there are limitations associated with the radial diffusion assay, the bacterial membrane permeabilisation assay provides more definitive antibacterial activity data and the combined results of both assays serve to confirm that eppin has a greater effect on P. aeruginosa than $S$. aureus. In order to investigate the immunomodulatory effects of eppin, our studies focused on the effects of eppin on LPS signalling and downstream responses in human monocytic cells and macrophages. Pre-treatment of THP-1 monocytic cells, THP-1 monocyte-derived macrophages and murine BMDMs with eppin prior to LPS stimulation 
significantly decreased production of chemokines such as IL-8 and MIP-2. The anti-inflammatory effect of eppin was also demonstrated in an in vivo model of LPS-induced acute lung inflammation. Treatment of mice with recombinant human eppin resulted in a significant reduction in pulmonary neutrophilia and a concomitant reduction in BALF levels of the neutrophil chemoattractant MIP-2.

Investigation of a potential mechanism to explain these findings demonstrated that eppin reduced NF- $\kappa \mathrm{B}$ activity in THP-1 monocytic cells in response to LPS stimulation. In contrast to SLPI [27], the anti-inflammatory effects of eppin were not dependent on binding of eppin to NF- $\kappa$ B DNA binding sites. However, similar to SLPI and elafin, we observed increased levels of phosphorylated I $\mathrm{B} \alpha$ in cells pre-treated with eppin. It is not clear why incubation of cells with eppin results in increased phosphorylated I $\mathrm{I} B \alpha$. Evaluation of proteasome activity has previously shown that the chymotrypsin, trypsin nor caspase-like activities of the proteasome are affected by SLPI or elafin [26, 28]. Therefore, it is possible that eppin affects the ubiquitin-proteasome pathway at other site(s), leading to increased I $\mathrm{KB} \alpha$ phosphorylation, decreased NF- $\mathrm{BB}$ activity and decreased expression of NF- $\mathrm{KB}$ target genes.

Moreover, we demonstrated the presence of eppin in human tissue and airway secretions, and showed an immunomodulatory role for eppin in vivo. As discussed earlier, SLPI and elafin play several important roles in the innate immune response. The expression of eppin in myeloid and epithelial cell types, coupled with its documented biological activity, suggest that eppin may play a protective role in the innate immune response similar to SLPI and elafin. The importance of this potential role remains to be fully explored; however, eppin may represent another important multifaceted member of the WFDC family.

\section{Acknowledgements}

Author contributions: C.C. Taggart and S. Weldon were involved in study design and conceptualisation. A. Scott, A. Glasgow, D. Small, S. Carlile, M. McCrudden, D. McLean, R. Brown, D. Doherty and U.I. Hamid performed experiments. C.C. Taggart and S. Weldon were involved in supervision of the experiments. C.C. Taggart, S. Weldon, C.M. O'Kane, D.F. McAuley, F.T. Lundy, M. Brodlie, D.J. Timson, C.R. Irwin, M. Tunney and J.S. Elborn were involved in drafting the manuscript for important intellectual content and providing important clinical samples. The final version was critically reviewed and approved by all authors.

\section{References}

1 Clauss A, Lilja H, Lundwall A. A locus on human chromosome 20 contains several genes expressing protease inhibitor domains with homology to whey acidic protein. Biochem J 2002; 368: 233-242.

2 Richardson RT, Sivashanmugam P, Hall SH, et al. Cloning and sequencing of human Eppin: a novel family of protease inhibitors expressed in the epididymis and testis. Gene 2001; 270: 93-102.

3 Wang Z, Widgren EE, Richardson RT, et al. Characterization of an eppin protein complex from human semen and spermatozoa. Biol Reprod 2007; 77: 476-484.

4 O’Rand MG, Widgren EE, Hamil KG, et al. Functional studies of eppin. Biochem Soc Trans 2011; 39: 1447-1449.

5 Yenugu S, Richardson RT, Sivashanmugam P, et al. Antimicrobial activity of human EPPIN, an androgen-regulated, sperm-bound protein with a whey acidic protein motif. Biol Reprod 2004; 71: 1484-1490.

6 O'Rand MG, Widgren EE, Hamil KG, et al. Epididymal protein targets: a brief history of the development of epididymal protease inhibitor as a contraceptive. J Androl 2011; 32: 698-704.

7 Bingle CD, Vyakarnam A. Novel innate immune functions of the whey acidic protein family. Trends Immunol 2008; 29: 444-453.

8 Fritz H. Human mucus proteinase inhibitor (human MPI). Human seminal inhibitor I (HUSI-I), antileukoprotease (ALP), secretory leukocyte protease inhibitor (SLPI). Biol Chem Hoppe Seyler 1988; 369: Suppl., 79-82.

9 McCrudden MTC, Dafforn TR, Houston DF, et al. Functional domains of the human epididymal protease inhibitor, eppin. FEBS J 2008; 275: 1742-1750.

10 Meckelein B, Nikiforov T, Clemen A, et al. The location of inhibitory specificities in human mucus proteinase inhibitor (MPI): separate expression of the $\mathrm{COOH}$-terminal domain yields an active inhibitor of three different proteinases. Protein Eng 1990; 3: 215-220.

11 Kramps JA, Klasen EC. Characterization of a low molecular weight anti-elastase isolated from human bronchial secretion. Exp Lung Res 1985; 9: 151-165.

12 Hiemstra PS, Maassen RJ, Stolk J, et al. Antibacterial activity of antileukoprotease. Infect Immun 1996; 64: 4520-4524.

13 Bingle L, Singleton V, Bingle CD. The putative ovarian tumour marker gene HE4 (WFDC2), is expressed in normal tissues and undergoes complex alternative splicing to yield multiple protein isoforms. Oncogene 2002; 21: 2768-2773.

14 Bingle L, Cross SS, High AS, et al. WFDC2 (HE4): a potential role in the innate immunity of the oral cavity and respiratory tract and the development of adenocarcinomas of the lung. Respir Res 2006; 7: 61.

15 Saitoh H, Masuda T, Shimura S, et al. Secretion and gene expression of secretory leukocyte protease inhibitor by human airway submucosal glands. Am J Physiol Lung Cell Mol Physiol 2001; 280: L79-L87.

16 Sallenave JM, Shulmann J, Crossley J, et al. Regulation of secretory leukocyte proteinase inhibitor (SLPI) and elastase-specific inhibitor (ESI/elafin) in human airway epithelial cells by cytokines and neutrophilic enzymes. Am J Respir Cell Mol Biol 1994; 11: 733-741.

17 Mihaila A, Tremblay GM. Human alveolar macrophages express elafin and secretory leukocyte protease inhibitor. Z Naturforsch C 2001; 56: 291-297.

18 Sallenave JM, Si Tahar M, Cox G, et al. Secretory leukocyte proteinase inhibitor is a major leukocyte elastase inhibitor in human neutrophils. J Leukoc Biol 1997; 61: 695-702. 
19 Westin U, Polling A, Ljungkrantz I, et al. Identification of SLPI (secretory leukocyte protease inhibitor) in human mast cells using immunohistochemistry and in situ hybridisation. Biol Chem 1999; 380: 489-493.

20 Jin FY, Nathan C, Radzioch D, et al. Secretory leukocyte protease inhibitor: a macrophage product induced by and antagonistic to bacterial lipopolysaccharide. Cell 1997; 88: 417-426.

21 King AE, Morgan K, Sallenave J-M, et al. Differential regulation of secretory leukocyte protease inhibitor and elafin by progesterone. Biochem Biophys Res Commun 2003; 310: 594-599.

22 Fahey JV, Wright JA, Shen L, et al. Estradiol selectively regulates innate immune function by polarized human uterine epithelial cells in culture. Mucosal Immunol 2008; 1: 317-325.

23 Scott A, Weldon S, Taggart CC. SLPI and elafin: multifunctional antiproteases of the WFDC family. Biochem Soc Trans 2011; 39: 1437-1440.

24 Wilkinson TS, Roghanian A, Simpson AJ, et al. WAP domain proteins as modulators of mucosal immunity. Biochem Soc Trans 2011; 39: 1409-1415.

25 Ding A, Thieblemont N, Zhu J, et al. Secretory leukocyte protease inhibitor interferes with uptake of lipopolysaccharide by macrophages. Infect Immun 1999; 67: 4485-4489.

26 Taggart CC, Greene CM, McElvaney NG, et al. Secretory leucoprotease inhibitor prevents lipopolysaccharide-induced IkappaBalpha degradation without affecting phosphorylation or ubiquitination. J Biol Chem 2002; 277: 33648-33653.

27 Taggart CC, Cryan S-A, Weldon S, et al. Secretory leucoprotease inhibitor binds to NF-kappaB binding sites in monocytes and inhibits p65 binding. J Exp Med 2005; 202: 1659-1668.

28 Butler MW, Robertson I, Greene CM, et al. Elafin prevents lipopolysaccharide-induced AP-1 and NF-kappaB activation via an effect on the ubiquitin-proteasome pathway. J Biol Chem 2006; 281: 34730-34735.

29 Gruenert DC, Basbaum CB, Welsh MJ, et al. Characterization of human tracheal epithelial cells transformed by an origin-defective simian virus 40. Proc Natl Acad Sci USA 1988; 85: 5951-5955.

30 Cozens AL, Yezzi MJ, Kunzelmann K, et al. CFTR expression and chloride secretion in polarized immortal human bronchial epithelial cells. Am J Respir Cell Mol Biol 1994; 10: 38-47.

31 Wessel D, Flügge UI. A method for the quantitative recovery of protein in dilute solution in the presence of detergents and lipids. Anal Biochem 1984; 138: 141-143.

32 Glasgow AMA, Small DM, Scott A, et al. A role for whey acidic protein four-disulfide-core 12 (WFDC12) in the regulation of the inflammatory response in the lung. Thorax 2015; 70: 426-432.

33 Lee JW, Fang X, Gupta N, et al. Allogeneic human mesenchymal stem cells for treatment of E. coli endotoxin-induced acute lung injury in the ex vivo perfused human lung. Proc Natl Acad Sci USA 2009; 106: 16357-16362.

34 Velarde MC, Parisek SI, Eason RR, et al. The secretory leukocyte protease inhibitor gene is a target of epidermal growth factor receptor action in endometrial epithelial cells. J Endocrinol 2005; 184: 141-151.

35 Jaumann F, Elssner A, Mazur G, et al. Transforming growth factor-betal is a potent inhibitor of secretory leukoprotease inhibitor expression in a bronchial epithelial cell line. Munich Lung Transplant Group. Eur Respir J 2000; 15: 1052-1057.

36 Kirchhoff C, Habben I, Ivell R, et al. A major human epididymis-specific cDNA encodes a protein with sequence homology to extracellular proteinase inhibitors. Biol Reprod 1991; 45: 350-357.

37 Katsha AM, Ohkouchi S, Xin $\mathrm{H}$, et al. Paracrine factors of multipotent stromal cells ameliorate lung injury in an elastase-induced emphysema model. Mol Ther 2011; 19: 196-203. 